This item was submitted to Loughborough's Research Repository by the author.

Items in Figshare are protected by copyright, with all rights reserved, unless otherwise indicated.

\title{
BIM and the small construction firm: a critical perspective
}

PLEASE CITE THE PUBLISHED VERSION

http://dx.doi.org/10.1080/09613218.2017.1293940

PUBLISHER

(C) Taylor \& Francis

VERSION

AM (Accepted Manuscript)

\section{PUBLISHER STATEMENT}

This work is made available according to the conditions of the Creative Commons Attribution-NonCommercialNoDerivatives 4.0 International (CC BY-NC-ND 4.0) licence. Full details of this licence are available at: https://creativecommons.org/licenses/by-nc-nd/4.0/

\section{LICENCE}

CC BY-NC-ND 4.0

\section{REPOSITORY RECORD}

Dainty, Andrew, Roine Leiringer, Scott Fernie, and Chris F. Harty. 2017. "BIM and the Small Construction Firm: A Critical Perspective”. Loughborough University. https://hdl.handle.net/2134/24305. 


\title{
BIM AND THE SMALL CONSTRUCTION FIRM: A CRITICAL PERSPECTIVE
}

\author{
Andrew Dainty, ${ }^{1}$ Roine Leiringer ${ }^{2}$, Scott Fernie ${ }^{3}$ and Chis Harty ${ }^{4}$
}

\begin{abstract}
The need for technological and administrative innovation is a recurrent theme in the UK construction reform agenda, but generic improvement recipes are beginning to give way to a more focused prescription; Building Information Modelling (BIM). The current strategy is to mandate the use of BIM for government projects as a way of integrating the design, construction and operation of publically procured buildings. This aspiration represents a partial turn away from a focus on managerialist agendas towards a belief in the power of digital practices to achieve the aspiration of integrated working, collaboration and innovation, a trend that is being reflected globally in relation to both national and firm-level policy interventions. In this paper we subject this 'BIM revolution' to critical scrutiny. By drawing on theories of the digital divide we develop a critical discourse around the ways in which political reform agendas centred on BIM might not stimulate innovation on a wider scale, but could act to disenfranchise small firms who are unable (or unwilling) to engage with them. This critical analysis presents important new research questions around the technocratic optimism which pervades the current reform discourse, the trajectory of industry development that it creates, and the policy process itself.

\footnotetext{
${ }^{1}$ Professor, Loughborough University, UK, a.r.j.dainty@lboro.ac.uk

2 Associate Professor, University of Hong Kong, China, roine.leiringer@hku.hk

${ }^{3}$ Senior Lecturer, Loughborough University, UK, s.fernie@lboro.ac.uk

${ }^{4}$ Professor, University of Reading, UK, c.f.harty@reading.ac.uk
} 
KEYWORDS: BIM, Policy Implementation, critical discourse, SMEs, Digital Technologies, Digital Divide, policy process. 


\section{INTRODUCTION}

The UK construction industry is constantly berated for its under-performance (Fernie et al. 2006). A succession of government-backed reports have variously criticized the sector for its high costs, slow delivery, unsafe working practices and failure to innovate (e.g. Latham 1994, Egan 1998, Wolstenholme 2009). Much of this criticism can be at least partially attributed to the highly fragmented delivery structure that has beset the industry, where a myriad of loosely coupled organizations, often locked within zero-sum logics, deliver to lowest cost agendas. Approaches to reform have therefore focused on establishing ways of gluing the industry back together via a complex and piecemeal mix of both coercive and voluntary measures, none of which seems to have achieved the key performance goals laid down within reform documents.

Most recently, the Government has developed a slightly different approach to reform via two related Government Construction Strategies (Cabinet Office 2011; Infrastructure and Projects Authority 2016) and an Industrial Strategy (IS) (BIS 2013). The IS, in particular, represents a significant rhetorical shift towards a ‘partnership' between industry and government in delivering challenging performance targets. However, together the strategies also impose specific solutions on the industry to address the perceived performance failings of the past. One such 'solution' is Building Information Modelling (BIM). The Government Construction Strategy (Cabinet Office, 2011) sets a target "To introduce a progressive programme of

mandated use of fully collaborative Building Information Modelling for Government projects by 2016”, a policy shift that other countries have also begun to emulate (CIC 2014; Di Giacomo 2015). 
According to Khemlani (2011), the term BIM was first introduced into the architecture, engineering and construction (AEC) industry in the early 2000s, evolving from “.... a buzzword with handful of early adopters to the centrepiece of AEC technology". This is reflected in the most recent manifestation of the UK Government's Construction Strategy (Infrastructure and Projects Authority 2016:6), which states that "BIM is a collaborative way of working that facilitates early contractor involvement, underpinned by the digital technologies which unlock more efficient methods of designing, creating and maintaining our assets.”. There is seemingly no end to the hyperbole surrounding the potential of BIM to 'revolutionize' construction practice, through 'intelligence', 'efficiency' and 'Integrated Project Delivery', and even the academic literature has over the past decade been dominated by claims that the adoption of BIM can lead to improved efficiency (Aranda-Mena et al. 2009, Doumbouya et al. 2016), quality and collaboration ( Demian and Walters, 2014; Ingemansson Havenvid et al. 2016) and so on (see Miettinen and Paavola 2014). If we are to believe the hype surrounding BIM, its adoption will certainly represent a step-change in digitally-enabled working, or even a 'new paradigm' within AEC (cf. Azhar 2011).

Within the UK, there is no doubt that the wave of enthusiasm for BIM as an espoused panacea to the industry's ills has been buttressed by its positioning as a central plank of the UK Government's Industrial Strategy (BIS 2013:9), which states “.... only through the implementation of BIM will we be able to deliver more sustainable buildings, more quickly and more efficiently". This positioning of BIM as the 'only' possible mechanism to deliver on these three vital prongs of performance improvement has elevated it beyond a mandated technological improvement tool to become the foundation for the improvement agenda, and as the vehicle for realizing the 'radical, transformational change’ espoused within the IS (BIS 2013:25). As Green 
(2013:12) recently suggested, “.... it seemingly doesn't really matter what the problem is - the answer is always BIM".

In some respects the wave of enthusiasm for BIM is unsurprising given what is known about hype cycles linked to the introduction of new technologies, and specifically the role that expectation plays in shaping the ways in which such technologies play out (Van Lente et al. 2013; O’Leary 2008). However, technological innovation rarely yields the outcomes expected, and the nature of BIM adoption will be a product of both the technology itself and the specific context within which it is adopted (Linderoth 2010; Van Lente et al. 2013). It is surprising, therefore, that there has been relatively little critical commentary on either the technology itself, or the policy being used to mandate it. Although some have begun to question the hype surrounding BIM (e.g. Fox 2014), and others have begun to explore the perspectives of smaller firms (Poirier et al. 2015; Hong et al. 2016), there is a need for more critical perspectives on BIM to counterbalance the claims around industry-wide integration that have become so attached to the technology and the practices it promotes. As part of this, there is an acute need to explore BIM from the perspective of less powerful and influential actors in the industry - the small and medium-sized enterprises (SMEs) that account for the vast majority of firms operating in the sector (Hong et al. 2016). Such a perspective contributes towards an emerging perspective on BIM which sees firm context as an important mediator in its implementation and adoption (Poirier et al. 2015).

In order to begin to rebalance the commentary and expectation surrounding BIM, in this paper we subject its implementation to critical scrutiny. The aim here is not to deny the transformational power of BIM to influence construction practices which have been well rehearsed within the academic and industry literatures. Rather, the aim is to balance this 
dominant discourse by exploring the potential differential effects of this technology on the organizations that are expected to embrace it. An important point of departure here is our consideration of 'the enterprise' as our unit of analysis. As Sexton et al. (2006) suggest, it is organizations that should be seen as the focus for change in the construction industry rather than projects per se. Thus, given the structural dominance of small and medium sized organizations in the sector, we critique the rhetoric of BIM-inspired reform through the lens of small firm operation. Drawing on the theoretical perspectives offered by the digital divide (van Dijk 1999; 2005), and set broadly within the critical turn in management studies and the non-performative perspective that this promotes (Fournier and Grey 2000), we examine the possible unintended consequences of the technologically deterministic logics, which dominate the reform discourse. This provides a more critical perspective on the BIM policy mandate, and a countervailing position to the dominant rhetoric of BIM as a panacea to the industry's ills. It also means offering a different perspective and broadening the scope of research on BIM from focusing on its content, technical development and uptake (e.g. Riese, 2008; Tang et al., 2010) and application on projects (e.g. Linderoth, 2010) to put focus more firmly on the firm and the individuals of which it is made up. In applying this perspective we seek to position our contribution as complementary to institutional explanations of BIM adoption.

The paper begins by situating BIM within wider UK policy debates. Its emergence and establishment as a driver of change can be seen as a part of a broader set of deterministic change agendas that have beset the industry, many of which have failed to account for the very real structural challenges which await such prescriptions. Next, we examine the BIM agenda specifically, examining how the political processes of enactment are mediated through the process of organization, and some of the seldom rehearsed unintended consequences of BIM to 
construction practice. We then go on to explore BIM from the specific standpoint of the small firm. By drawing on theories of the digital divide we speculate as to both the potential differential effects that BIM might have on the myriad organizations expected to embrace it, and the resistance that BIM might face as an instrument of change within the sector. Both perspectives challenge perceptions of BIM enactment as a linear process of implementation. The concluding section highlights the potential tensions and unintended consequences that emerge from the technocratic optimism that undergirds this contemporary reform discourse and discusses the research agendas that might flow from it.

\section{CONSTRUCTION SECTOR POLICY AND THE BIM MANDATE}

The Industrial Strategy (IS) (BIS 2013) has been instrumental in framing the recent reform agenda in the UK construction industry. This sector-specific industrial policy is intricately connected to and/or informed by a broader suite of Government policy (see HM Treasury 2011, HM Government 2011, Heseltine 2012) and informs the recent 2016 Government Construction Strategy (Infrastructure and Projects Authority 2016). The construction industrial policy is also one amongst many sector specific Industrial Policies, but differs from most as construction is described as an 'enabling' sector (see BIS 2012a, BIS 2012b). As such, the industrial strategy for construction is not isolated from other powerful policy documents and sector strategies.

The current IS continues a well-established trajectory of attempts to reform the construction industry (see Murray and Langford 2003, Wolstenholme 2009) that have consistently fallen short in diffusing wholesale change in the sector (see Wolstenholme 2009). A key criticism has been that the reform agenda has been hegemonic (cf. Jensen et al. 2011), in that 
it privileges the concerns and interests of large contractors and clients (Fernie et al. 2006). This is particularly noteworthy given that $99.7 \%$ of all firms in the UK Construction industry employ less than 114 people (ONS 2016). Indeed, although the most recent incarnation of the Government Construction Strategy (2016) has SME’s writ-large in its ministerial foreword, and engagement with small firms has been a constant component of the reform landscape since at least the early 1990’s (see Latham 1994; Wolstenholme 2009), the extent to which SMEs have been given a voice in policy development is debatable. The emergence of initiatives such as knowledge transfer partnerships (e.g. Arayici et al. 2011) and advice forums such as BIM4SME (2016 - part of the UK the national BIM Task Group), support the argument that SME's are pivotal for policy implementation, but decisions regarding how, when and why SME's are engaged in the BIM policy process are unclear. Similarly, the policy network responsible, the evidence base used, and the actual process deployed remain hidden from scrutiny, as do attempts to learn from policy processes, content and outcomes.

Indeed, the formation, or restructuring, of new policy problems should arguably be preceded by a rigorous evaluation of previous policy problems, instruments, interventions, and measured impact. The purpose of this 'evaluation' is to address the concern that contemporary "[policy] failure can stem from governments and policy makers not effectively evaluating policy processes and learning useful lessons from past experiences” (Howlett et al. 2009:182-183). Evaluations differ though, and may emphasize agenda-setting, policy formulation, decision making, diffusion of instruments and the policy network itself. Alternatively, evaluations may focus on evaluating policy justification, needs, policy theory, implementation, impact and efficiency (Vega and Chiasson 2015). As such, evaluations can be directed to policy processes, content and outcomes. However, despite the rich body of arguments and available literature, 
practices and processes to guide and direct policy evaluation, the IS's sixty six word evaluation of previous reform policy seemingly falls short of any such 'evaluation', and the 'Digital Build Britain’ report (HM Government 2015), while bringing together both GCS 2011 and the IS (BIS 2013) to develop a strategic plan for delivering Level 3 BIM $^{\mathrm{i}}$, offers little reflection on either the policy process or networks surrounding its creation. Similarly, whilst the GCS 2016 does reflect on progress made since GCS 2011, it simply concedes that there is still some way to go to diffuse BIM Level 2. It is the lack of any clear evaluation of 'needs' that is particularly troubling within this policy domain, as there is little evidence that such policies have been sensitive to the nature, structure and distribution of the issues they seek to address. In sum, rather than providing comfort that there is continuity and learning from one policy cycle to another (or between public sector procurement policy and industrial strategy), the evaluations (or the argued lack thereof) resonate with Green's (2013:14) suspicions that we are right to have "concerns of an absence of corporate memory within Government".

Notwithstanding, it is important to concede that, whilst policy evaluation is understood as an important mechanism for learning, its location in the real world of politics means that such evaluation may become a destructive game of blame distribution and fault (Bovens et al. 2006). This is especially so where policies significantly fail to deliver on their aspirations and perhaps why policy evaluation may be considered "nothing but the continuation of politics by other means" (ibid:321). As such, it might be that particular voices are being privileged within the reform discourse, or at least that less powerful actors perspectives are suppressed. Indeed, the absence of the SME perspective in the BIM-driven reform discourse is surprising given that concerns about the exclusion of smaller firms from the digital economy have been foregrounded in other related policy arenas. The Government’s Digital Inclusion Strategy (Cabinet Office 
2014), for example, highlights that over a third of SMEs do not have a website; capital required to buy technology is out of their reach; and that many lack the necessary data and digital capability. It would seem, therefore, that consolidating public sector central procurement power to coerce the industry to reform is not necessarily driven by any significant engagement with the concerns and interests of the sectors largest economic constituency (SME's), nor based on a rigorous evaluation of previous and ongoing policy. This is even more surprising, given how established the idea is that policy, and particularly that related to IT diffusion (Edwards et al. 2007), needs to be sensitive to SME's (Vega and Chiasson 2015).

\section{BIM POLICY, BIM RHETORIC, BIM REALITY}

Some of the magnitude of the BIM revolution in the UK can be ascribed to the ambiguity of the term. Indeed, the literature is replete with BIM definitions and significant variation in what is, or is not, included in the term. The closest the report of the UK Government BIM Task Group gets to a universal definition of BIM is:

"Building Information Modelling and management is digital representation of physical and functional characteristics of a facility creating a shared knowledge resource for information about it forming a reliable basis for decisions during its life cycle, from earliest conception to demolition.” (2011:100)

The emphasis is therefore firmly on the digital model as a source of information (or 'knowledge') that can be used for informing decisions. Such definitions reify BIM as an uncontroversial, straightforward (if complex) artefact; it is fixed, certain and stable. Contracts, risk, ownership and other process implications are discussed, but they are represented as issues to deal with for organizations to 'do' BIM. There is little recognition of BIM as a heterogeneous 
assemblage of technologies, processes and people, introduced into an already complex landscape of projects, firms, contracts, professionals and technologies (see Harty 2005; Linderoth 2010).

BIM can, as argued above, be seen as part of the long tradition of criticisms of the construction sector, and associated calls for better integration, collaboration and innovation. However, past remedies such as total quality management (TQM) (continuous improvement and quality control principles), Lean construction (the application of lean manufacturing principles to construction) and partnering (supply chain alliancing) did not have quite the same sector-wide influence on industry discourse (cf. Green 2011). Even though actual impact of BIM is still rather uncertain, it is being touted as the solution to industry's problems. An example of this inflation of ambition, or 'BIM-hype', can be found in Richard Saxon's 'Growth Through BIM' report (Saxon 2013) from the Construction Industry Council which claims:

“'Better! Faster! Cheaper!' is the mantra of all who seek improved performance in a product or service. For decades this search in construction has been fruitless: cheaper or faster usually meant of lesser value; cost rose inexorably. Productivity growth has been flat whilst in other sectors it has risen hugely. Now we have the arrival of a way of working which promises to design and build assets more cheaply and faster but also to make them better performing. No wonder it [BIM] has been mandated as government policy.” (Saxon, 2013: 6)

This is intended to be slightly tongue in cheek, but is representative of the fervor surrounding BIM and its centrality to delivering on the priorities of those who espouse its capabilities. BIM has quickly been promoted to delivering Government-driven reform of the sector, both in terms of better value for money for the public purse, and in underpinning the promises made within the IS. Although the idea of BIM solving a host of long standing problems 
seems a long way from the definition of BIM as a digital model for better decision making, its role in effecting structural and cultural reform of the sector is now firmly established.

Awareness of BIM is also almost total in the UK, whether measured through industry surveys (e.g. NBS 2014) or academic studies (e.g. Davies and Harty 2013; Kim and Park 2013; Gledson et al. 2012). But actual use, on the other hand, is both less well embedded, and very difficult to capture through industry surveys. Firstly, there are few surveys that provide anything close to a specific definition of BIM and where they do it remains broad and vague. For instance, the McGraw-Hill 2009 'Business value of BIM' survey defines it as "the process of creating and using digital models for design, construction and/or operations of projects” (McGraw-Hill, 2009: 4). There is nothing here of process or practice reconfiguration, or to indicate what organizations, projects or people are actually doing. More recent surveys tend to drop any pretense of definition, instead presenting 'BIM' as stable and unchallenged. Secondly, these surveys are based on opinions rather than any evaluation of activities. Whilst professionals might overwhelmingly see BIM as requiring changes in practices or having the potential to increase productivity (e.g. NBS 2012;13), these surveys do not indicate whether changes are happening. Nor are they intended to. It could, instead be argued that they serve a purpose to propagate the rhetoric that BIM is something everyone needs to embrace. The fact that such reports are often accompanied by software vendor endorsement would support this. But more importantly, perhaps, these surveys are methodically rather limited, and simply conflate opinions with fact. They are, as such, not tools for interrogating use, or possible exclusion. However, they clearly show an increase in industry practitioners' awareness of 'BIM', and that practices and people are being mobilized within BIM discussions. 
A further problem concerns the lack of consistent and predictable outcomes when BIM is implemented. Research which has followed and documented these processes and impacts tends to describe a more fragmented and partial landscape of use (e.g., Miettinen and Paavola 2014; Succar 2009) and argues that context specificities lead to unforeseen outcomes, such as hybrid digital / analogue practices (Harty and Whyte, 2010) or the persistence of more traditional forms of collaboration even within BIM projects (Dossick and Neff, 2011). More broadly, diffusion of BIM technologies and processes across complex organizations has been seen to lead to parallel and inconsistent working practices (Shibeika and Harty, 2015) and standards (Eadie et al. 2016), The challenges of translating BIM processes from project to project have also been identified (Linderoth, 2010).

What is clear from these studies is the unpredictability of outcomes from implementation of complex ICT, which is undoubtedly reflected in current UK debates around competing standards and technologies, and the lack of effective scalable standard working practices emerging from the use of BIM. Very few of the numerous surveys conducted in the UK and internationally on 'BIM use' and uptake explicitly consider differences between large and small firms. One exception is the National Federation of Builders 2012 BIM-Readiness survey (NFB 2012) and 2014 follow up. The aim of the survey was to evaluate both current use, and awareness and appetite for BIM in light of the mandate, and samples 135 companies. The 2012 results show a distinct lack of BIM use amongst UK contractors generally (defined in the survey as the use of ' $3 \mathrm{D}$ drawings, clash detection tools, schedule integration tools or other BIM features') with $64 \%$ claiming to have never used them. But there is a clear divide when differentiating between large and SME contracting firms, with $21 \%$ of the former, and $73 \%$ of the latter having never used BIM. Related questions of attitudes towards BIM as a potential 
opportunity show a less marked, but still demarcated set of responses, with $78 \%$ of large and 57\% of SME contractors indicating that they believe BIM will bring benefits for their businesses. The clarity of understanding of BIM across these two groups is also uneven, with $25 \%$ of large firms stating familiarity with BIM levels and having considered implications of the mandate for their projects, but only $2.7 \%$ of SMEs claiming the same. Of specific interest here are the differences around training provision and intention, with only 10\% of SMEs planning to invest in training, 36\% intending to rely on 'free' seminar style training events, and $27 \%$ not planning on any training at all.

The 2014 follow up (NFB, 2014) was intended to gauge progress over two years. Whilst it is less exhaustive in terms of analysis, it concludes that "industry has not moved on much further since the last survey in terms of BIM adoption”, and although training provision had increased, SMEs were still lagging in terms of uptake and understanding compared to larger contractors, and "are still yet to understand the business benefits". Although this survey is little different in terms of robustness to other industry reports, it does serve to highlight perceptions around a firm-size divide in use. This is in line with the findings of numerous studies conducted on ICT uptake in general, in that small firms typically lag behind larger firms in the adoption of ICT (Arbore and Ordanini 2006; Bach et al. 2013; Dewan and Riggins 2005). There is clearly a need to better understand the perspectives of SMEs and the reasons for their lack of engagement in BIM.

\section{THE NEED FOR AN SME PERSPECTIVE}

The preceding overview has revealed the policy aspirations for BIM set within the broader reform context, its attractiveness as a performance solution, and also the widening gap 
between the espoused intentions of its use and the realities of its implementation. There exists, therefore, an acute need to take a view of BIM implementation from the perspectives of the firms expected to enact it, together with an acknowledgement of the differential engagements with the technology that the diversity of the industry promotes. Such analysis requires a more nuanced understanding of the structural characteristics of the sector, the heterogeneity of the firms that populate it, and the impact that this has on the ways in which they encounter and apprehend it. For example, whereas small professional services firms such as architects and engineering consultancies are likely to possess the ICT infrastructure and capacity to adopt digital design practices, indeed some might even be at the vanguard of BIM development, those involved in on-site production confront a more difficult context for embracing and utilizing such technologies. Within UK construction the dominance of such firms in terms of both construction output and employment, is absolute. While there is no universal definition of small-mediumsized enterprises (SMEs), the European Commission (EC) defines micro, small and medium sized enterprises as those employing less than 10, 50 and 250 people respectively (EC 2003). Such a definition renders the vast majority of construction firms small or micro. To put this into context, the most recent statistics from the Office for National Statistics Construction Statistics Annual Tables records 273,775 contracting firms operating in the UK construction sector, of which only 746 employed more than 114 people (ONS 2016). Small firms also accounted for over $70 \%$ of employment in the contracting sector. However, these headline figures mask an even more fragmented labor market structure given the very large number of self-employed workers that has been encouraged by a relatively benign taxation policy since the early 1980s (Briscoe et al. 2000). A recent analysis revealed that some 54\% of manual workers can be classified as self-employed within the sector, twice that of the UK economy as a whole, albeit 
that many such workers operate under false self-employment arrangements (Behling and Harvey 2015). As such, the dominance of small and micro businesses represents a deeply ingrained structural characteristic of UK construction that 'hegemonic' reform policies rarely account for.

While a detailed examination of the characteristics of small firms is beyond the scope of this paper, it is important to briefly examine the extent to which they are able to embrace new technologies. Indeed, the impact of firm size on the capabilities of small construction businesses represents a burgeoning area of enquiry within the construction organization and management literature, particularly in relation to the role it plays in innovation (e.g. Sexton and Barrett 2003; Barrett et al. 2008; Hardie and Newell 2011). Essentially, smaller firms lack the capacity - or organizational slack - to invest in embracing technological tools and processes (Ritchie and Brindley, 2005). This raises questions as to the extent to which small firms are able to successfully adopt - and ultimately capitalize upon - the possibilities afforded by digital technologies (Bach et al. 2013). For example, in the context of BIM a survey by Gledson et al. (2012) revealed that larger companies benefit from a greater awareness and capacity for planning for implementation. Similarly, Poirier et al. (2015) suggest that an SME’s ability to benefit from BIM requires a clear strategy for guiding its adoption; in reality few will have the capacity to develop a systematic approach. It is little surprise, therefore, that almost three quarters of SME contracting firms have never used BIM (NFB 2012) and that only around 5\% have even attempted Level 3 (Hosseini et al 2016). And yet, as we suggest above, the policy process has ignored the endemic disadvantages that such firms face in their reform agenda and the market differentiation that this is likely to stimulate. It is to this issue that we now turn.

\section{THE DIGITAL DIVIDE}


The idea that benefits derived from information and communication development technologies (ICTs) are inequitably distributed has been extensively discussed in policy circles since the early 1990s (Epstein et al. 2011; Selwyn, 2004). Commonly the issue has been portrayed as persistent gaps between developed and developing countries, as well as domestically along the lines of gender, education, age, geography and socioeconomic aspects. These gaps in access and usage of ICTs have become known as the 'digital divide'; a concept which has been deployed across a range of academic and policy discourses (Epstein et al. 2011), and adopted at different abstraction levels such as individuals, households, businesses and geographic areas (Cruz-Jesus et al. 2012). Originally focus was centered on the problem of material access and the simple dichotomy of those 'who have' and those 'who have not'. More recently the debate has evolved to include the problem of usage; commonly referred to as first and second order effects (Dewan and Riggins 2005). Today most conceptualizations of the digital divide include four main parts: attitudes, access, skills and types of usage (van Deursen and van Dijk, 2014). Issues commonly included are the degrees of: physical and material access, sufficient motivation, appropriate skills and usage opportunity. While the general literature on the digital divide has evolved around the use of the Internet, focus has over time expanded to include a more diverse range of ICTs (cf. Selwyn, 2004), including both general use ICTs, such as email, as well as more elaborate production-integrating ICTs linked to design and production processes (Bach et al. 2013; Luchetti and Sterlacchini, 2004). There is an emerging body of work that applies the concept to organizations in general, applying terms such as: the business digital divide (Arendt, 2008; Wielicki and Arendt, 2010); the corporate digital divide (Bach et al., 2013; Forman, 2005); and the organizational digital divide (Dewan and Riggins, 2005). Studies within this domain refer not only to ICT access, but also the ability of appropriate use of the technology. 
Of particular interest here is the sub-section of this literature that deals explicitly with SMEs (e.g. Martin and Halstead, 2004; Arendt, 2008; Taylor, 2015).

Whilst multiple frameworks for understanding the digital divide in general, and the broad adoption/diffusion of ICT in SMEs more specifically, have been developed over the past two decades, the seminal framework is provided by Van Dijk (1999; 2005). This provides the following distinctions in terms of generalized barriers to the use of ICTs: (i) lack of elementary digital experience caused by lack of interest and inclination to use ICTs, and a general unattractiveness of the new technology (motivational access); (ii) no possession or access to the relevant hardware and software (material access); (iii) lack of digital skills caused by insufficient user friendliness and lack of education and training (skills access); (iv) lack of significant usage opportunities (usage access). These four access stages are further described below.

\section{Motivational access}

Motivational access is the precursor to the other three phases of access to any particular ICT. In simple terms, it is the motivation for the potential users (e.g. owners, managers and employees - see Dewan and Riggins, 2005) to adopt, acquire, learn and use the technology. As such, the notion of motivational access is shaped by attitudes towards the technology (van Deursen and van Dijk, 2015). Hence, for some it is not so much a question of 'have' or 'have not' as it is a question of 'want' or 'want not'. The reasons behind a lack of motivation are many and varied, and are by no means trivial as they span both individual and collective levels. Furthermore, they are formed by cultural, material, mental, social and temporal resources. It could be rather straightforward reasons such as a lack of interest, time, money and skills, but also more complex and difficult to grasp explanations such as technophobia, computer anxiety, lack 
of self-confidence, and the image of self in relationship to the technology (van Dijk, 2005). It follows that a lack of motivation can be both rational and emotional and have its origin in: no need for use or for significant usage opportunities; no time or liking, rejection of the medium; lack of money; and lack of skills (ibid.). It could also be the case that the technology in question is perceived to be flawed in terms of user-friendliness, usefulness, attractiveness and affordability. It is important to remember though that a lack of motivation is not limited to the reluctant. It is also present among those adopters who rarely, or irregularly, use the technology (Weilicki and Arendt, 2010).

\section{Material access}

After motivation comes the concept of material access. Having material access is a necessary condition for the development of the skills and ability needed to use the technology (Fleet, 2012). This includes physical access to hardware, software and services (van Deursen and van Dijk, 2015). As noted above, material access has long been the main focus of digital divide research, as well as in the broader area of policymaking (Epstein et al., 2011), and the prevailing view has tended to be that the material divide narrows over time as technologies become more mature and prices (supposedly) go down (van Dijk, 2005). This follows the traditional diffusion model of innovators, early adopters, majority of early and late users, and the laggards. However, such a trajectory is much more likely for relatively stable, easy to identify, technology such as telephones and tablets, than it is for computer media that constitutes a bundle of continually changing pieces of hardware and software with evolving functionality (ibid.).

\section{Skills access}


Following on from acquiring the necessary motivational and material access comes the need for the development of skills needed to use the technology in question. This entails some sort of effort to be made to operate and use the new medium, commonly through practice or some kind of formal education (van Dijk, 2005). This means to establish the collection of skills necessary to operate the ICT (hardware and software) and its networks, to be able to search, select and process information, and to have the capacity to use the ICT to achieve specific goals (ibid.), i.e. digital skills are situational and go far beyond merely being able to operate a computer (Selwyn, 2004). It is generally accepted in the digital divide literature that the differences in skills access provides a bigger digital gap than that of material access (Qureshi, 2014; van Deursen and van Dijk, 2014; 2015). It is also generally accepted that ICT skills are not predominantly acquired through various forms of formal education such as courses, operation manuals, and help functions. Rather such skills acquisition comes through learning through practice, trial and error, and by asking other skilled actors (Martin and Halstead, 2004; van Dijk, 2005).

\section{Usage access}

Usage is the underlying goal of the process of appropriation of a particular ICT. In terms of usage having the motivation, material access and the skills to use ICT does not really matter if there is no need, occasion, obligation or effort to actually use the technology (Weilicki and Arendt, 2010). Hence, usage access goes beyond the technological properties of ICT, such as hardware and software, to include a broad range of economic, social, cultural and political factors (van Dijk, 2005). Some advanced applications are for example difficult for an average user to use, while other parts of the system might be relatively simple. Furthermore, some 
applications require expensive hardware and software and might require continuous upgrading and access to specialist applications. Finally, there is potential for biased content in which the software will favour particular interests, languages, and digital skills (ibid.). It follows, that usage of any particular ICT will differ between different categories of users, and that usage gaps will emerge (Lucchetti and Sterlacchini, 2004).

\section{Digital access barriers to BIM}

It is clear from the argument presented in previous sections that the BIM agenda and policy discourse, similarly to many previous attempts to promote digital technologies, has been preoccupied with the material access barrier. The degree of 'technocratic optimism' is high and the general perception seems to be that once all firms have the relevant hardware and software they will use BIM, and be BIM compliant. Such a stance, linking general ownership with BIM compliance, is understandable as it suits policy debates (Epstein et al. 2011; Muir and Oppenheim, 2001); it provides a clear definition of the problem and also a very easy solution in terms of investment. It does, however, take a rather static view of what BIM is; effectively overlooking that it is dynamic in nature (Miettinen and Paavola, 2014; Succar 2009) and, indeed, is better conceptualized as a bundle of continually changing pieces of hardware and software with evolving functionality. It also effectively overlooks questions regarding motivation, skills and the resources necessary to deploy the technology. As the literature on the digital divide clearly shows, moving from awareness (as shown in the BIM uptake surveys) to actual use is a huge step (Bach et al., 2013), especially if the only real motivation comes from coercion.

The motivational access barrier is handily swept aside in the policy debate. From an organizational point of view the argument put forward rests on that given the size of the public 
sector construction market firms will fall in line and invest. This might over time be true for large firms, but how many SMEs can afford to focus on centrally procured public sector work? If seen from the individual worker (employee) level this is, in simple terms, seen as a temporary problem that will go away as the current workforce is gradually replaced with individuals that have grown up with ICT. To a degree this is of course true, but such a position effectively disregards the body of knowledge on the digital divide altogether. In the UK, as in many other countries, the workforce is ageing; for the foreseeable future a large part of the workforce will still be made up of those who have not grown up in a 'digital world' and who follow highly structurally ingrained non-digital modes of working that form an integral part of their personal and professional sense of self-esteem. For them the introduction of new ways of working through BIM is likely to blur responsibilities (Mäki and Kerosuo, 2015), create new roles (Poirier et al, 2016) and reduce professional autonomy (Jaradat et al., 2013), which in turn provides challenges at both a rational and emotional level and requires a substantial degree of unlearning (Kokkonen and Alin, 2016).

There is a strong link between motivational access, the propensity to use ICT and the skills required to do so. It is not surprising, therefore, that the skills access barrier also is commonly considered to be a temporary phenomenon, and that the problem of inadequate digital skills is reduced to the skills of operating and managing hardware and software (cf. van Dijk and Hacker, 2003). From a BIM mandate perspective the skills access barrier is looked at as an investment issue in terms of training existing staff or hiring new staff who possess the necessary skills. That the costs and effort involved in doing so are not the same across different types of organizations is seemingly conveniently forgotten. Furthermore, it is important to remember that training is neither high on the agenda for SMEs (NFB 2012; 2014) nor is it considered to be very 
effective in developing digital skills. Ultimately, developing and retaining the needed skill sets comes from actual usage.

The fourth and final general barrier, the lack of usage opportunities, is omitted from policy altogether. From the general perspective this is perceived as a matter of free choice and, therefore, not seen as a problem (cf. van Dijk and Hacker, 2003). It follows logically, that in a context where BIM is considered to be a real opportunity for the involved companies little attention will be given to the issue. However, usage access in terms of getting to work on BIM projects remains a very real problem for a large proportion of firms. There are significant differences in the financial capabilities of firms in the construction sector and many SMEs are effectively blocked out from working on major projects. Others might have the capacity to do so, but are still subjected to competition and are not in a position where regular use of the technology will be guaranteed. This in turn affects their inclination to invest in BIM, or more accurately in the material and skills access necessary to be BIM compliant.

\section{DISCUSSION: POSSIBLE IMPLICATIONS OF THE 'BIM REVOLUTION'}

There is a small but growing body of academic research which has begun to examine the 'real world' implementation of BIM processes in organizations and projects, and a good deal of these conclude that there are numerous barriers and challenges that stop it seamlessly replacing existing ways of doing things (e.g. Blasé and Manley 2004; Harty 2008; Arayici et al. 2011; Hosseini 2016). These publications often cite those existing sets of relations and practices as the problem or the risks associated with the return on investment in such technology. We argue here that what so far has been missing is a more overt consideration of firm size as a determinant of engagement with BIM. As Sexton et al. (2006:21) suggest, “.... there is a need to appreciate that 
both small and large construction companies are different species that live in different business market habitats, that must behave in different ways in order to adapt and succeed, and which need different sources and types of knowledge and technology to remain nourished and healthy." This is a perspective which has clearly failed to resonate with policy makers.

It follows from the arguments presented above that a growing digital divide in the construction sector between those who 'do' and those who 'do not do' BIM is inevitable. Or perhaps more accurately, a 'BIM gap' exists between those firms who can afford to invest in hardware and software, the right kind of people and training, and have reasonable continuity in BIM usage; and those who cannot. For smaller firms, and especially those who work across public and private sector markets, investment in such technologies are unlikely to be justified, especially where efficiencies and productivity gains cannot be guaranteed across their entire market portfolios.

The policy discourse and how BIM adoption is framed clearly has a role to play here. The discourse consistently leans against the rhetoric of technological opportunity and BIM is unfailingly presented as a solution to achieving integration, a phenomenon that is reflected across many developed nations (Wong et al., 2010). Part of this clamor of support for BIM as panacea is no doubt down to its materiality. This makes it somewhat different from previous initiatives such as Partnering and Lean, in having a technological substance which can be represented physically as a reified object, and hence, rationally and unproblematically. The dominant reform discourse portrays no uncertainty in its inherent abilities, and the way to reap the benefits of BIM is thus promoted in terms of overcoming the material access barrier. The current preoccupation with return on investment in industry reports (eg McGraw-Hill 2014) reflects this unproblematic, transaction-based position. This reductionism, in turn, is enforced through attempts to enforce 
adoption through procurement processes that emphasize BIM compliance. This framing of the issue and how adoption is enforced places responsibility firmly with the adopters and their motivation. Compliance requires having the necessary capacity for uptake, as well as operating in a business environment where it is considered favorable and necessary to do so. Hence, from a policy perspective the BIM discourse is framed in such a way that it serves those who already have resources and power. This is what is generally known in the digital divide literature (and elsewhere) as the 'Matthew Effect', whereby the rich get richer (cf. Pearce and Rice, 2013). Even if the argument could be made that everybody stands to benefit (i.e., that SMEs will eventually take up and benefit from the technology), those with the most resources adopt first, gain more skills, and have more usage access. Thus, they are likely to get earlier and greater benefits, thereby increasing rather than decreasing inequalities in the market.

The inevitable corollary of the BIM mandate will be to create a two tier market where benefits are mostly accrued by the already most privileged and the less powerful are marginalized (see Cushman and McLean, 2008). This reveals a potential fracture between the two types of policy in play. On the one hand, GCS 2011 and GCS 2016 use compliance as a way to overcome the material access barrier. If, on the other hand, we were to shift the focus towards skills access usage access, then BIM becomes a potential problem rather than a solution, and onus is placed more firmly on IS to deal with the issues of adoption and implementation, offering alternatives that are not compliance driven (cf. Epstein et al. 2011). However, the IS, whilst recognizing skills gaps in the sector, is largely blind to the specific needs of SMEs to overcome skills access with little explication of interventions to address skills and usage access.

All of this considered, it would seem that a continued reliance on BIM as an agent of change raises several important questions. The first concerns the unintended consequences of 
relying upon a small number of BIM compliant organizations. It is undeniable that BIM capability strengthens the competitive positions of those organizations which have the capability to exploit it. As Poirier et al. (2015) have shown in a Canadian context, BIM offers real potential even for small firms if the right contextual conditions exist for its implementation. But this begs the question what these contextual conditions are. We would argue that it is clearly not simply a matter of having the financial resources to invest in BIM, nor is it as simple as putting in place a policy that coerces firms to do so. Material access is merely a small part of the story and is dwarfed by the potential impact of usage access. Mandated in the wrong way, BIM has the potential to create power asymmetries that could have damaging implications for the sector and what it produces. At the very least, the extent to which less competition would yield greater value for money for public sector investment seems questionable.

Given the above, it is little wonder that the gap between leading edge firms and SMEs in the adoption of BIM has widened (Mellon and Kouider, 2016). However, even if this is accepted, then a second question emerges as to whether the two-speed industry and a widening gap between the haves and have-nots is likely to yield the more integrated delivery model that the BIM-hype espouses? Rather, it might well serve to further enhance already existing inequalities in the sector. Thus, while it is possible to ascribe too much technocratic agency to digital practices, it would seem that BIM has the potential to divide as much as it integrates.

A third question emerges around motivational barriers and what would happen if SMEs (whether as first tier suppliers or as sub-contractors) steadfastly refuse to adopt BIM in the ways that it is mandated, holding implementation at Level 2 (or less) with the resultant failure of this central plank of the reform agenda. Indeed, a rather curious aspect of the BIM mandate concerns the gap between what is actually prescribed, and the rhetoric of collaboration and improvement 
that surrounds it. 'BIM Level 2' compliance is defined as: “managed 3D environment held in separate discipline "BIM" tools with attached data. Commercial data managed by an ERP. Integration on the basis of proprietary interfaces or bespoke middleware could be regarded as "pBIM" (proprietary). The approach may utilise 4D programme data and 5D cost elements as well as feed operational systems" (BIM working party 2011: 16). This notably modest, partial definition appears disconnected from operation, with separate systems, tailored interfaces between them and the suggestion that integration with time and cost data is not essential. Thus, the BIM-reality diverges from the BIM-hype described above and perhaps reflects the engagement of the firms expected to enact it. Ironically, the industry's structural reliance on small firms to deliver the physical aspects of construction renders them powerful agents in this regard, and their continued dominance is testament to their resilience in the face of even the deepest institutional reform agendas. Indeed, it tends to be the reform agendas that are discarded rather than the organizations expected to embrace them. While it is impossible to speculate how exactly BIM implementation will play out in coming years, it is clear that the current policy trajectory demands a more critical research agenda that challenges practices that are being normalized through the policy discourse.

\section{CONCLUSIONS}

In this paper we have revealed something of the potential unintended consequences of the 'BIM revolution'. The intention here is not to provide an evidence-based critique of BIM and its effectiveness, but to stimulate new debates around its role as a central plank of the reform agenda, and to question the policy process itself. There is no doubt that BIM represents an 
exciting technology with the potential to improve the efficiency, connectivity and performance of many AEC processes. However, its rhetorical attractiveness as a way of reconnecting the fragmented delivery network has elevated this technology to an almost mythical status within the policy discourse. While the root of the technocratic optimism that underpins this unerring belief in the transformational role of digital practices is difficult to establish, the power asymmetries likely to flow from its enforced use are deeply troubling for those who lack the resources to embrace it. Indeed, the question of whose interests BIM principally serves is arguably obfuscated by the hype that now surrounds it and by its mobilization across disparate policy networks; on the one hand it appears to be concerned with facilitating better value for money for public sector procurement agencies via the GCS (2011 and 2016). On the other hand, it is also central to resolving perceived market failures highlighted in the industrial policy regarding the private sectors ability to deliver on productivity, sustainability and economic growth aspirations. Despite the BIM mandate, surveys reveal that the reform policy has failed to engage SMEs with BIM, and have seemingly failed to account for the digital divide that will inevitably follow. That resistance to the wholesale uptake of BIM is emerging is unsurprising. What is more surprising is how much faith has been placed in digital technology, and how it has been positioned as a panacea to virtually all of the deeply ingrained issues that a succession of reform initiatives has failed to address.

In this paper we have suggested that BIM uptake is likely to be more problematic for smaller firms without the resources or capacity to invest in the technology. However, although our focus has been to critically examine BIM adoption from the perspective of the digitally disenfranchised small firm, it is worth noting that there are likely to be just as many people working in larger firms that will be just as affected by the barriers of motivational and skills 
access to such technologies. In other words, the differential effects of BIM and the divide it creates are just as likely to be felt within large organizations as they are across their supply chains. As such, although the expectations of BIM will undoubtedly subside as its adoption moves through the hype cycle, it is important that the implications of the current policy-push for BIM are critically considered for other constituencies. Too much technocratic optimism could have damaging consequences for the industry should the digital divide be opened up in other ways, and so must be sensitively considered in relation to the structural and cultural contexts that it is supposed to benefit.

A more critical research agenda is now required which explores the differential implications of the BIM policy approach across the varying constituencies of the industry that it is likely to affect. This should examine the institutional factors shaping its implementation, and should attend to the asymmetries of power that such technology enactment inevitably invokes across disparate firms and contexts. Given that many BIM studies begin by citing the mandate as motivation, it is perhaps surprising that there are none that question or reflect on the effects of that mandate, or place policy and regulatory impacts within their analytical scope. A deeper understanding of the BIM mandate therefore requires policy studies that evaluate and challenge the processes, networks, power relations, and outcomes of BIM policy, and justify the technical concerns that it creates. Clearly, BIM policy is not the only area of construction policy that lacks such scrutiny and reflection. Whilst there has been some good progress in opening up debates on construction policy recently (see Foxell and Cooper, 2015; Smiley, et al., 2014), further scrutiny of the policy process might offer a useful starting point to structure questions that explore why certain interests are privileged over others. Such questions might scrutinize for example: the emergence and legitimacy of policy ideas such as BIM and collaboration; what constitutes 
'evidence' and where and why it is used in the policy process; and power relations and connections within and between development and implementation networks. Of course, all of these suggestions assume that construction policy (including BIM) is designed to have an impact on practice. It currently remains to be seen whether BIM is a means to an end, or an end in itself.

\section{ACKNOWLEDGMENT}

An earlier version of this paper was presented at the EPOC Conference 2015. We are grateful to the referees of this paper for their insightful comments and suggestions in developing the arguments set out here, as well as to the referees and editors of this Special Issue.

\section{REFERENCES}

Aranda-Mena, G. Crawford, J., Chevez, A. and Froese, T.(2009) Building Information Modelling Demystified: Does it Make Business Sense to Adopt BIM? International Journal of Managing Projects in Business, 2(3), 419-434.

Arayici, Y., Coates, P., Koskela, L., Kagioglou, M., Usher, C., and O'Reilly, K. (2011) BIM adoption and implementation for architectural practices. Structural Survey, 29(1), 7-25.

Arayici, Y., Coates, P., Koskela, L., Kagioglou, M., Usher, C., and O'Reilly, K. (2011) Technology adoption in the BIM implementation for lean architectural practice. Automation in Construction 20(2), 189-195

Arbore, A. and Ordanini, A. (2006) Broadband divide among SMEs. International Small Business Journal, 24(1), 83-99. 
Arendt, L. (2008) Barriers to ICT adoption in SMEs - How to bridge the digital divide. Journal of Systems and Information Technology, 10(2), 93-108.

Azhar, S. (2011) Building information modeling (BIM): Trends, benefits, risks, and challenges for the AEC industry. Leadership and Management in Engineering, 11(3), 241-252.

Bach, M.P., Zoroja, J. and Vuksic. V.B. (2013) Review of the corporate digital divide research: a decadal analysis (2003-2012). International Journal of Information Systems and Project Management, 1(4), 41-55.

Barrett, P., Sexton, M., and Lee, A. (2008) Innovation in small construction firms. Taylor \& Francis, London. .

Behling, F. and Harvey, M. (2015) The evolution of false self-employment in the British construction industry: a neo-Polanyian account of labour market formation. Work, Employment and Society, 29(6), 969-988..

BIM Working Party (2011) BIM management for value, cost and carbon improvement. Department for Business, Innovation and Skills, London.

BIM4SME (2016) Accessed November 2016. http://www.bim4sme.org/

BIS (2012a) Economics paper No. 18: Using Industrial Strategy to help the UK economy and business compete and grow. Department for Business, Innovation \& Skills, London.

BIS (2012b) Industrial strategy: UK sector analysis. Department for Business, Innovation \& Skills (BIS), London, September 2012

BIS (2013) Industrial strategy: government and industry in partnership: Construction 2025. Department for Business, Innovation \& Skills, London.

Blayse, A.M. and Manley, K., (2004)Key influences on construction innovation. Construction Innovation, 4(3), 143 - 154. 
Bovens, M., Hart, P., and Kuipers, S. (2006). The politics of policy evaluation. In M. Moran, M. Rein and R.E. Goodin (Eds) The Oxford Handbook of Public Policy, Oxford University Press, Oxford, 319-335.

Briscoe, G., Dainty, A. and Millett, S. (2000) The impact of the tax system on self-employment in the British construction industry. International Journal of Manpower, 21(8), 596-614.

Cabinet Office (2011) Government Construction Strategy. Cabinet Office, London.

Cabinet Office (2014) Government Digital Inclusion Strategy., Cabinet Office, London.

CIC (2014). Roadmap for Building Information Modelling Strategic Implementation in Hong Kong's Construction Industry. Construction Industry Council, Hong Kong Special Administrative Region.

Cruz-Jesus, F., Oliveira, T. and Bacao, F. (2012) Digital divide across the European Union. Information \& Management, 49. 278-291.

Cushman, M. and McLean, R. (2008) Guest editorial: exclusion, inclusion and changing the face of information systems research. Information Technology and People, 21(3), 213-221.

Davies, R. and Harty, C. (2013) Measurement and exploration of individual beliefs about the consequences of building information modelling use. Construction Management and Economics, 31(11), 1110-1127.

Demian, P. and Walters, D. (2014) The advantages of information management through building information modelling. Construction Management and Economics, 32(12), 1153-1165.

Dewan, S. and Riggins, F.J. (2005) The digital divide: current and future research directions. Journal of the Association for Information Systems, 6(12), 298-337.

Di Giacomo, E. (2015). BIM, trends from around the world. European BIM Summit, Barcelona $2015-\quad$ February $13^{\text {th }}$, Available at 
http://numerique.tech.fr/Barcelona_BIM_Summit_Feb_13th_EDG150213_P.pdf [Accessed 16 June 2016].

Dossick, C.S. and Neff, G. (2011) Messy talk and clean technology: communication, problemsolving and collaboration using Building Information Modelling. The Engineering Project Organization Journal, 1(2), 83-93.

Doumbouya, L. , Gao, G. , and Guan, C. (2016). Adoption of the Building Information Modeling (BIM) for Construction Project Effectiveness: The Review of BIM Benefits. American Journal of Civil Engineering and Architecture, 4(3), 74-79.

Edwards, T., Delbridge, R., and Munday, M. (2007). A Critical Assessment of the Evaluation of EU Interventions for Innovation in the SME Sector in Wales. Urban Studies, 44(12), 24292447.

Eadie, R., Browne, M., Odeyinka, H., McKeown, C. and McNiff, S. (2015) "A survey of current status of and perceived changes required for BIM adoption in the UK", Built Environment Project and Asset Management, 5(1), pp.4 - 21

Egan, J. (1998) Rethinking Construction: Report of the Construction Task Force. HMSO, London.

Epstein, D., Nisbet, E.C. and Gillespie, T. (2011) Who's responsible for the digital divide? Public perceptions and policy implications. The Information Society, 27, 92-104.

European Commission (2003) The new SME definition User guide \& model declaration. European Commission. Available at https://web.archive.org/web/20060718032542/http://ec.europa.eu/enterprise/enterprise_polic y/sme_definition/index_en.htm, accessed on $1^{\text {st }}$ February 2017 
Fernie, S., Leiringer, R., and Thorpe, T. (2006). Change in construction: a critical perspective. Building Research \& Information, 34(2), 91-103.

Fleet, G.J. (2012) Evidence of stalled ICT adoption and the facilitator ecommerce adoption model in SMEs. International Journal of the Academic Business World, 6(2), 7-18.

Forman. C. (2005) The corporate digital divide: determinants of internet adoption. Management Science, 51(4), 641-654.

Fournier, V., and Grey, C. (2000) At the critical moment: Conditions and prospects for critical management studies. Human relations, 53(1), 7-32.

Fox, S. (2014). Getting real about BIM: Critical realist descriptions as an alternative to the naïve framing and multiple fallacies of hype. International Journal of Managing Projects in Business, 7(3), 405-422.

Foxell, S. and Cooper, I. (2015) Closing the policy gaps. Building Research \& Information 43(4), 399-406.

Gledson, B, Henry, D and Bleanch, P (2012) Does size matter? Experiences and perspectives of BIM implementation from large and SME construction contractors. In: 1st UK Academic Conference on Building Information Management (BIM) 2012, 5-7 September 2012, Northumbria University, Newcastle upon Tyne, UK

Green, S.D. (2013) At it again. Construction Research and Innovation, 4(3), 12-15.

Green, S. D. (2011) Making sense of construction improvement. Wiley-Blackwell, Oxford.

Green, S.D. (1998) The technocratic totalitarianism of construction process improvement: a critical perspective. Engineering, Construction and Architectural Management, 5(4) 376 386. 
Hardie, M., and Newell, G. (2011) Factors influencing technical innovation in construction SMEs: an Australian perspective. Engineering, Construction and Architectural Management, 18(6), 618-636.

Harty, C.F. (2005) Innovation in construction: a sociology of technology approach. Building Research and Information, 33(6), 512-522.

Harty, C.F. (2008) Implementing innovation in construction: Contexts, relative boundedness and actor-network theory. Construction Management and Economics, 26(10), 1029-1041.

Harty, C. \& Whyte, J. (2010) The role of media in construction design work and ecologies of practice. American Society of Civil Engineers Journal of Construction and Engineering Management, 136(4) 468-476.

Heseltine, M. (2012) No stone unturned: in pursuit of growth, a report commissioned by the Prime Minister for the Chancellor of the Exchequer and the Secretary of State for Business, Crown, London

HM Government (2011) Laying the foundations: A Housing Strategy for England. HM Government, London

HM Treasury \& BIS (2011) The plan for Growth. HM Treasury \& Department for Business, Innovation \& Skills (BIS), Crown, London

Hong, Y., Sepasgozar, S. M. and Akbarnezhad, A. (2016) Factors influencing BIM Adoption in Small and Medium Sized Construction Organizations. In Proceedings of the International Symposium on Automation and Robotics in Construction (Vol. 33, p. 1). Vilnius Gediminas Technical University, Department of Construction Economics \& Property.

Hosseini, M. R., Banihashemi, S., Chileshe, N., Namzadi, M. O., Udaeja, C., Rameezdeen, R., and McCuen, T. (2016) BIM adoption within Australian Small and Medium-sized 
Enterprises (SMEs): an innovation diffusion model. Construction Economics and Building, 16(3), 71-86.

Howlett, M., Ramesh, M. and Perl, A. (3rd Ed) (2009) Studying Public Policy: Policy cycles \& policy subsystems. Oxford University Press, Ontario, Canada

Infrastructure and Projects Authority (2016) Government Construction Strategy 2016-20, Crown, London.

Ingemansson Havenvid, M., Hulthén, K., Linné, Å., and Sundquist, V. (2016) Renewal in construction projects: tracing effects of client requirements. Construction Management and Economics, 34(11), 790-807.

Jaradat, S., Whyte, J. and Luck, R. (2013). Professionalism in digitally mediated project work, Building Research \& Information, 41(1), 51-59.

Jensen, J.S., Gottlieb, S.C. and Thuesen, C.L. (2011) Construction sector development: frames and governance responses, Building Research \& Information, 39(6), 665-677.

Khemlani, L. (2011) Preface. In Eastman, C., Teicholz, P., Sacks, R. and Liston, K. (2011) BIM Handbook: A Guide to Building Information Modelling ( $2^{\text {nd }}$. Ed.), Wiley, New Jersey. pp xixiv.

Kim, P. K. and Park, K. S. (2013) BIM feasibility study for housing refurbishment projects in the UK. Organization, Technology and Management in Construction: An International Journal, 5, 765-774

Kokkonen, A. and Ahlin, P. (2016) Practitioners deconstructing and reconstructing practices when responding to the implementation of BIM. Construction Management and Economics, 34(7-8), 578-591.

Latham, M. (1994) Constructing the Team: Joint Review of Procurement and Contractual Arrangements in the United Kingdom Construction Industry, HMSO, London.Linderoth, 
H.C. (2010) Understanding adoption and use of BIM as the creation of actor networks. Automation in Construction, 19(1), 66-72.

Lucchetti, R. and Sterlacchini, A. (2004) The adoption of ICT among SMEs: evidence from an Italian survey. Small Business Economics, 23, 151-168.

Martin, L.M. and Halstead, A (2004) Attracting micro-enterprises to learning: community initiatives or growth incentives. Community, Work \& Family, 7(1), 29-42.

Mellon, S. and Kouider, T. (2016) SMEs and Level 2 BIM, The way forward, in Antonio Galiano Garrigós and Tahar Kouider(eds.). Healthy Buildings: Innovation, Design \& Technology, ICAT 2016: Conference Proceedings of the 6th International Congress of Architectural Technology, University of Alicante 12-14 May 2016. San Vicente del Raspeig: Universidad de Alicante, 2016. 121-135.

Miettinen, R. and Paavola, S. (2014) Beyond the BIM utopia: Approaches to the development and implementation of building information modelling. Automation in Construction, 43(1), 84-91.

McGraw-Hill (2009). The business value of BIM . McGraw-Hill Construction, New York McGraw-Hill (2014). The business value of BIM for construction in major global markets . McGraw-Hill Construction, New York

Muir, A. and Oppenheim, C. (2002) National information policy developments worldwide II: universal access - addressing the digital divide. Journal of Information Science, 28(4), 263273.

Murray, M and Langford, D. (eds) (2003) Construction Reports 1944-98. Blackwell, Oxford. 
Mäki, T. and Kerosuo, H. (2015) Site managers' daily work and the uses of building information modelling in construction site management. Construction Management and Economics, 33(3), 163-175.

NBS (2012) NBS National BIM Report 2012. National Building Specification, Newcastle UK

NBS (2014) NBS National BIM Report 2014. National Building Specification, Newcastle UK.

NFB (2012) NFB BIM readiness survey 2012 - BIM: Ready or not?. National Federation of Builders, Crawley, UK.

NFB (2014) NFB BIM Contractor Survey Final Report. National Federation of Builders, Crawley, UK.

Office for National Statistics (2016) Construction Statistics Annual Table: Number 17: 2016, https://www.ons.gov.uk/businessindustryandtrade/constructionindustry/datasets/construction statisticsannualtables, accessed on $1^{\text {st }}$ February 2017

O'Leary, D.E. (2008) Gartner's hype cycle and information system research issues. International Journal Accounting Information Systems, 9(4), 240-252

Pearce, K.E. and Rice, R.E. (2013) Digital divides from access to activities: comparing mobile and personal computer internet users. Journal of Communication, 63, 721-744.

Poirier, E., Forgues, D. and Staub-French, s. (2016) Collaboration through innovation: implications for expertise in the AEC sector. Construction Management and Economics, 34(11), 769-789.

Poirier, E., Staub-French, S., and Forgues, D. (2015). Embedded contexts of innovation: BIM adoption and implementation for a specialty contracting SME. Construction Innovation, 15(1), $42-65$. 
Qureshi, S. (2014) Overcoming technological determinism in understanding the digital divide: where do we go from here?. Information Technology for Development, 20(3), 215-217.

Riese, M. (2008) One Island East, Hong Kong: A Case Study in Construction Virtual Prototyping. In P. Brandon and T. Kocatürk (eds): Virtual Futures for Design, Construction \& Procurement. Blackwell Publishing Ltd., Oxford.

Ritchie, B. and Brindley, C. (2005) ICT adoption by SMEs: implications for relationships and management. New Technology, Work and Employment, 20, 205-217.

Saxon, R. (2013) Growth Through BIM. Construction Industry Council, London.

Selwyn, N. (2004) Reconsidering political and popular understandings of the digital divide. New Media \& Society, 6(3), 341-362.

Sexton, M., and Barrett, P. (2003) A literature synthesis of innovation in small construction firms: insights, ambiguities and questions. Construction Management and Economics, 21(6), 613-622.

Sexton, M., Barrett, P. and Aouad, G. (2006) Motivating small construction companies to adopt new technology. Building Research \& Information, 34(1), 11-22.

Shibeika and Harty (2015) Diffusion of digital innovation in construction: a case study of a UK engineering firm. Construction Management and Economics 33(5-6), 435-466.

Smiley, J-P., Fernie, S. and Dainty, A.R.J. (2014) Understanding Construction Reform Discourses. Construction Management and Economics, Volume 32, Issue 7-8, August 2014, pages 804-815.

Succar, B. (2009) Building information modelling framework: A research and delivery foundation for industry stakeholders. Automation in Construction, 18(3), 357-375. 
Taylor, P. (2015) The Importance of Information and Communication Technologies (ICTs): An Integration of the Extant Literature on ICT Adoption in Small and Medium Enterprises, International Journal of Economics, Commerce and Management, 3(5), 274-295.

Tang, P., Huber, D., Akinci, B., Lipman, R. and Lytle, A. (2010). Automatic reconstruction of as-built building information models from laser-scanned point clouds: A review of related techniques. Automation in construction, 19(7), 829-843.

van Deursen, A. and van Dijk, J. (2014) The digital divide shifts to difference in usage. New Media and Society, 16(3). 507-526.

van Deursen, A. and van Dijk, J. (2015) Toward a multifaceted model of internet access for understanding digital divides: an empirical investigation. The Information Society, 31, 379391.

van Dijk, J. (1999) The Network Society: Social aspects of new media. SAGE. Thousand Oaks, CA.

van Dijk, J. (2005) The Deepening Divide: Inequality in the Information Society. SAGE. Thousand Oaks, CA.

van Dijk, J. and Hacker, K. (2003) The digital divide as a complex and dynamic phenomenon. The Information Society, 19, 315-326.

Van Lente, H., Spitters, C., and Peine, A. (2013). Comparing technological hype cycles: Towards a theory. Technological Forecasting and Social Change, 80(8), 1615-1628.

Vega, A., and Chiasson, M. (2015). Towards a comprehensive framework for the evaluation of small and medium enterprise policy. Evaluation, 21(3), 359-375. 
Wielicki, T. and Arendt, L. (2010) A knowledge-driven shift in perception of ICT implementation barriers: Comparative study of US and European SMEs. Journal of Information Science, 36(2), 162-174.

Wolstenholme, A. (2009) Never waste a good crisis: a review of progress since Rethinking Construction. Constructing Excellence, London.

Wong, A. K., Wong, F. K., and Nadeem, A. (2010) Attributes of building information modelling implementations in various countries. Architectural Engineering and Design Management, 6(4), 288-302.

\section{Endnote}

${ }^{\mathrm{i}}$ According to the BIM task group, BIM can be categorized according to maturity levels. Level 1 is simply the use of a managed CAD environment. Level 2, which the UK Government mandate requires, is a 3D environment with cross disciplinary integration based on proprietary interfaces; i.e. the integration is at the level of exchange formats rather than the tools used by each part of the supply chain. Level 3 is seen as a fully open, compliant and inter-operable single shared environment. 